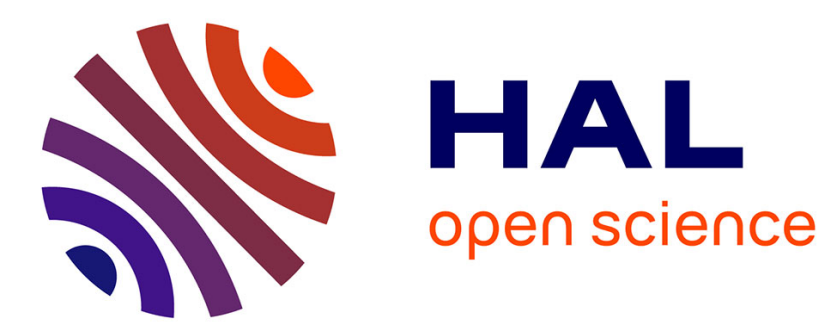

\title{
"Beyond 3D printers": Understanding Long-Term Digital Fabrication Practices for the Education of Visually Impaired or Blind Youth
}

\author{
Emeline Brulé, Gilles Bailly
}

\section{- To cite this version:}

Emeline Brulé, Gilles Bailly. "Beyond 3D printers": Understanding Long-Term Digital Fabrication Practices for the Education of Visually Impaired or Blind Youth. Proceedings of the CHI conference, ACM, 2021, tokyo, Japan. 10.1145/3411764.3445403 . hal-03107912

\section{HAL Id: hal-03107912 https://hal.science/hal-03107912}

Submitted on 12 Jan 2021

HAL is a multi-disciplinary open access archive for the deposit and dissemination of scientific research documents, whether they are published or not. The documents may come from teaching and research institutions in France or abroad, or from public or private research centers.
L'archive ouverte pluridisciplinaire HAL, est destinée au dépôt et à la diffusion de documents scientifiques de niveau recherche, publiés ou non, émanant des établissements d'enseignement et de recherche français ou étrangers, des laboratoires publics ou privés. 


\title{
"Beyond 3D printers": Understanding Long-Term Digital Fabrication Practices for the Education of Visually Impaired or Blind Youth
}

\author{
EMELINE BRULÉ, University of Sussex
}

GILLES BAILLY, Sorbonne Université, CNRS, ISIR
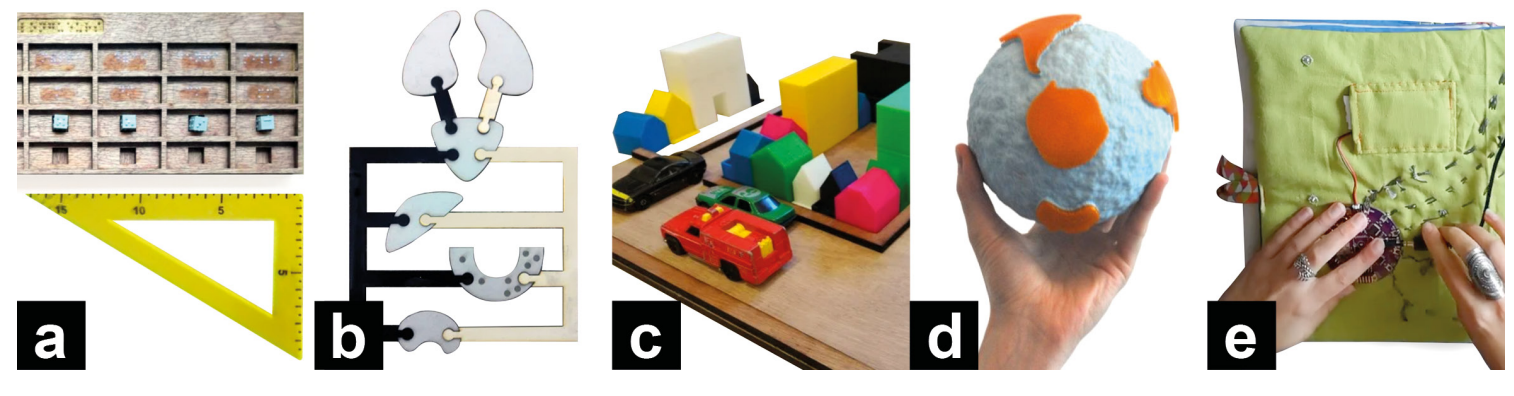

Fig. 1. Although digital fabrication did not replace traditional techniques for producing accessible tactile media, laser cutting was promptly adopted for creating educational tools and accessories such as [a] this conversion table with braille cubes, replacing some tactile transcription and this accessible square; or [b] representations of concepts with rich textures, here a puzzle circulatory system. 3D printing has a narrower range of applications: while professionals adopt it for some manipulable representations of space, such as [c] a model of a street block, printed complex 3D representations are not often needed, less agreeable to manipulate, and examples such as [d] tactile globes could not be designed or printed internally. Finally, electronic prototyping platforms can augment representations or teaching tools to support students' engagement, like [e] interactive tactile books using a Lilypad controller. However, interactive projects are difficult to maintain, require skilled volunteers and remain at the periphery of practices.

Disability professionals could use digital fabrication tools to provide customised assistive technologies or accessible media beneficial to the education of Blind or visually impaired youth. However, there is little documentation of long-term practices with these tools by professionals in this field, limiting our ability to support their work. We report on such practices in a French organisation, providing disability educational services and using digital fabrication since 2013, for six years. We trace how professionals defined how digital fabrication could and should be used through a range of projects, based on pedagogical uses and the constraints in creation, production and maintenance. We outline new research perspectives going beyond 3D printers and its promises of automation to embrace hybrid approaches currently supported by laser cutters, the learning and documentation process, and the production of accessible tactile media at a regional or national scale.

CCS Concepts: • Human-centered computing $\rightarrow$ Empirical studies in accessibility; Accessibility; Empirical studies in collaborative and social computing; Field studies; • Social and professional topics $\rightarrow$ People with disabilities.

Additional Key Words and Phrases: Disability; Do-It-Yourself; Making; Social Design; Fablab; Maker Space; 3D Printing; Activity Theory; Inclusive Innovation; School; Tactile; Workplace

Publication rights licensed to ACM. ACM acknowledges that this contribution was authored or co-authored by an employee, contractor or affiliate of a national government. As such, the Government retains a nonexclusive, royalty-free right to publish or reproduce this article, or to allow others to do so, for Government purposes only.

๑ 2021 Copyright held by the owner/author(s). Publication rights licensed to ACM.

Manuscript submitted to ACM 


\section{ACM Reference Format:}

Emeline Brulé and Gilles Bailly. 2021. "Beyond 3D printers": Understanding Long-Term Digital Fabrication Practices for the Education of Visually Impaired or Blind Youth. In CHI Conference on Human Factors in Computing Systems (CHI '21), May 8-13, 2021, Yokohama, Japan. ACM, New York, NY, USA, 22 pages. https://doi.org/10.1145/3411764.3445403

\section{INTRODUCTION}

"People with disabilities are the original lifehackers" [33]: they and their communities have long engaged in adapting, creating, or repairing assistive technologies [61]. The widespread availability of consumer grade digital fabrication tools such as $3 \mathrm{~d}$ printers combined with the online instantaneous sharing of models [11, 44] opens new opportunities in this area, referred to as Do-It-Yourself Assistive Technologies (DIY-ATs) [32]. Adequate software could enable a wider range of stakeholders, including families and non-expert volunteers, to customize or design new products [26]; and support disability professionals such as occupational therapists in providing expanded services [6, 48]. Producing assistive technologies, from prosthetic limbs to accessible tactile media, could be faster and cheaper.

However, we currently have limited insights into if and how disability support services appropriate digital fabrication tools, in particular educational services for Blind or visually impaired youth ${ }^{1}$. Inquiries into design and production difficulties (e.g., for accessible tactile media [50]) or disability community and professionals' perceptions of the potential of digital fabrication (e.g., [30, 48]) provide only snapshots into actual practices. Furthermore, they are mostly based on self-reports, hence may not account for the gap between opinions and practices. Investigation of practices as they are undertaken (e.g., [6, 22]) often span a year or less. Research-based modelling tools for supporting the creation of 3D printed accessible tactile media (e.g., tactile moving pictures [36] or maps [47]) are not evaluated in the field over time.

In this paper, we investigate the long-term adoption of digital fabrication tools in the context of assistive technologies. We conducted a 6 year-long participatory study (2014-2020) at a French organisation, "AdaptSchool", providing support and educational services, including assistive technologies and accessible tactile media, to Blind or visually impaired youth. We documented 50 projects participants produced using digital fabrication tools during that period and contextualise them in the organisation's activities using our interviews (34) and observations (approx. 400h) data, to describe empirically how disability professionals progressively integrated digital fabrication in their work and determined what it could be used for.

After extensive design explorations, the professionals found most 3D printed media fell short of their pedagogical and design expectations, in addition to be lengthy and complex to produce. By contrast, laser cutting was easily integrated into existing practices, as it affords more control over creating new and richer representations, among other uses. Surprisingly, laser cutting became a tool of choice not only for two-dimensional (2D) and bas-relief (2.5D) representations, but also for three-dimensional (3D) representations when they are needed. However, AdaptSchool's managers did not always perceive the learning gains from using these representations to justify their costs. But these costs could not be lessened, as their design could not be outsourced to volunteers. In contrast, most projects built upon electronic prototyping platforms were produced through an initiative relying on external volunteers, and the initiative was evaluated by its impact on students' engagement and how it embodied an innovative practices and mindset. We thus can consider electronics as successfully adopted, but they remain at the periphery of everyday practices.

When used, digital fabrication was integrated in broader craft practices, from painting to sewing, which could potentially be supported by hybrid [56] modelling tools. Professionals argue, and our observations support, that

\footnotetext{
${ }^{1}$ There are many debates surrounding the use of person first or identity first language to refer to participants, as well as the use of capitalization [7, 20]
} We use identity-first language and capitalize Blind, as this is a growing demand of this community. 
developing practices with digital fabrication would primarily require better coordination and expertise sharing between organisations as well as increased financial and organisational support, not only for creating but also for producing and documenting DIY-ATs. We further suggest there is potential to develop better tools to model 3D representations from 2D materials. In summary, our contributions are to:

- Describe long-term practices with digital fabrication for the education of Blind and visually impaired children, which also provides a case-study of the conditions under which digital fabrication changes work beyond the engineering and design industry;

- Describe the design space of the accessible media and other educational objects created by disability professionals;

- Outline a research agenda for DIY-ATs in this domain.

\section{BACKGROUND: MAKING FOR ACCESSIBILITY}

HCI scholars have explored the potential of digital fabrication for making assistive technologies for 10 years (e.g. $[27,32,48,54])$. This is rooted in a much longer tradition of Do-It-Yourself assistive technologies and knowledge exchange by, with and for people with disabilities [25, 61] and the success of open source software which appeared transferable to the physical realm [11]. This section contextualises our research in the larger DIY-AT scholarship before focusing on the known challenges of making for visually impaired and Blind children.

\subsection{Digital fabrication for DIY-ATs}

Consumer-grade digital fabrication and prototyping tools (digital fabrication for short) refer to Computer Numerical controlled machines enabling the production of physical artifacts from digital models. In the past fifteen years, they have become widely available [40]. Among these tools, 3D printers and laser cutters are the most widespread and used by amateurs [11]. Customer-grade 3D printers enable the fabrication and reproduction of plastic-made artifacts from a digital 3D model by printing layers on top of each other, a process known as Fusion Deposition Modeling. Laser cutters afford the precise cutting or engraving of sheets of material (less than a centimeter thick, generally), such as fabric, wood, or acrylic. Additionally, many electronic prototyping platforms (e.g. Arduino boards) have become popular.

These tools are part of a larger learning ecosystem aiming at enabling anyone to engage in creating, producing and sharing new objects. This includes: 1) easy-to-use and access modelling software; 2) collaborative workshops owning digital fabrication tools and making them available for a free or a small fee to support decentralized and small-scale production, while 3) enabling situated and collaborative learning; and 4) platforms to share tutorials and models [32, 44]. Compared to earlier initiatives in DIY assistive technologies that were largely restricted in practice to people with a technical background (e.g., [57]), the digital fabrication ecosystem lowers barriers to entry.

Assistive technologies are "any item, piece of equipment, or product system, whether acquired commercially, modified, or customized, that is used to increase, maintain, or improve functional capabilities of individuals with disabilities" [59]. Due to their personalised nature, they necessitate the intervention of experts in short supply (such as occupational therapists, orthotists, and prosthetists) and have a high market price, while being often abandoned for not meeting user needs [10]. Therefore, scholars have investigated which ATs designs could be improved using digital fabrication (for instance through customisation [26]) and how they could be provided at a lower price point. For instance, this could require reducing the complexity of the process through custom software to disability professionals to become makers [6], enlisting the help of makers [26] and providing models to print free of charge [5]. Actual impact on the delivery of 
ATs is however unclear [43]: for instance, Slegers et al.[48] find that occupational therapists become less likely to think 3D printing will affect their practices after having received training in using it.

\subsection{Digital fabrication for Blind or visually impaired children}

Visual impairments refer to a broad range of visual abilities, from mild visual impairment to legal (light perceptions) and total blindness [62]. There is a low prevalence of visual impairments during childhood in European countries, and they are often associated with other impairments, such as physical and sensory impairments, learning disabilities or behavioral disorders [37]. Studies on the use of digital fabrication for this group largely focus on accessible tactile media (e.g., [29, 50-53]).

Accessible tactile media are "representations of visual information that can be accessed through the sense of touch or medium, that when touched, evoke meta-representations" [50]. They are often unavailable outside of special education institutions or community organisations, despite the availability of online libraries (e.g., on BTactile.com), as many production techniques require specialised equipment. As 3D printers are arguably the most widespread digital fabrication tools, they have been proposed to produce 3D scaled models [3], 2.5D representations (similar to bas-reliefs [36]), and 2D outlines [54] for a range of educational needs, such as literacy [15, 53], geography and history [3, 4, 22, 23, 46], sciences, technologies, engineering and mathematics (STEM) [6,23, 31], art [50], and independent living skills such as locomotion and mobility [2,28].

However, the impact of 3D printing on learning and tactile reading experience remains unclear. Some experimental research suggests that it could improve learning outcomes compared to earlier techniques, by enabling shape exploration [34] or by using depth [28] and audio interaction [22]. But exploratory studies of 3D printing in primary school suggest that mainstream models (e.g., animals, figurines, buildings) are more difficult for children to interpret than toys $[3,15]$. This could partially be explained by children's lack of familiarity with the 3D print compared to toys they may also own. But the tactile quality of the model and the print can also hinder understanding, and using plastic is limiting especially for younger children [15].

As the ability to 3D print accessible tactile media appears guaranteed, other researchers turned to the challenge of enabling anyone to create new tactile media. One approach is to design task-specific tools enabling members of children's communities to create tactile media. For instance, scholars have proposed a variety of tools for creating interactive media [24, 46, 55] or tangible editors for 3D printed maps [47]. Others have instead focused on understanding how to support collaboration with domain experts (e.g., transcribers), technical experts (e.g., makers with knowledge of CAD modelling, programmers [23]) and other stakeholders such as family members [51]. However to realise these promises, we need a better understanding of how different modes of tactile representations compare and likely, better standards and shared practices for their creation [50].

We have limited insights into how professionals involved in the education of visually impaired and Blind children have adopted digital fabrication [50]. However, Buehler et al. [6] found that a special education school had rapidly abandoned their 3D printer, due to infrastructure costs such as technical support and difficulties with creating new models. Therefore, scholars have investigated how digital fabrication fits in with other means of creating accessible tactile media, such as specialised equipment and crafts. For instance, Serrano-Mira et al. [45] discuss the use of 3D printers to create molds for thermoformed tactile graphics; Stangl et al. [50] describe the use of many different tools (braille embossers, etc) in the community. Moreover, this body of research rarely focuses on the uses of digital fabrication for children who are visually impaired but not Blind or children with multiple impairments including blindness. Therefore 
we ask: what are the challenges and opportunities emerging when digital fabrication is used longitudinally to produce DIY-ATs for the education of all Blind and visually impaired children?

\section{APPROACH}

This study is part of a larger research project investigating the schooling of visually impaired students in France. This research was ethnographic and participatory, and sought to support practitioners in reflecting and effecting change on their practices.

\subsection{Research Site}

We conducted our field study at a French non-profit organisation providing support and educational services to 120 visually impaired youth (from birth to 20 years-old), hereby referred to as AdaptSchool. The organisation provides: special education support and adapted documents to visually impaired youth attending inclusive mainstream schools; special education classrooms; educational support (e.g., speech therapy, support to families); training in independent living skills (e.g., occupational therapy, mobility and locomotion skills or training in using residual vision abilities). The young people receiving services are Blind or visually impaired, with or without additional disabilities. This organisation has 5 professional transcribers in addition to trained special education teachers who adapt all the material needed by children at school, including many tactile graphics.

We chose this organisation because it has become involved in making early, in 2013, and is a highly engaged participant in a national network of organisations collaborating on the making of DIY-ATs for visually impaired youth. They organise multiple events bringing makers and practitioners together, and employees create multiple learning resources for their peers in over organisations. It was described by interviewees at other organisations, who participated to the same research project, as particularly advanced in the use of digital fabrication. Moreover, it has a long collaboration with a nearby university and a willingness to collaborate with researchers. As for the field researcher, they have a background as design practitioner and experience as maker, and were especially welcome by the practitioners due to their ability and willingness to assist with ongoing projects. In summary, this organisation might differ from others due to their high willingness to use digital fabrication, awareness of the research literature and resulting expertise. It is also distinct from countries with limited provision of tactile media and texts such as the United States [9, 50].

\subsection{Methods and Participants}

We used a mixed set of qualitative methods. We conducted observations for one week a month (except school holidays) between September 2014 and June 2016. Around 400 hours of these observations (documented through field-notes) related to use of digital fabrication. This included informal discussions reflecting on practices and how the objects made were used by professionals, children and teenagers. We continued to collaborate regularly on digital fabrication projects until June 2018 and remained casually involved, generating additional informal exchanges such as emails or other design documentations. From 2014 to 2020, we also conducted yearly semi-structured interviews about uses of digital fabrication with the employee who had been using digital fabrication since 2013 and help colleagues get started; and with other employees as they started or continued using digital fabrication or using artifacts produced this way. In total, we conducted 34 in-depth interviews on site with 11 participants holding different occupations (IT support, transcribers, occupational therapists, locomotion and mobility instructors, social educators, specialised teachers). Apart for one Blind teacher, they were all sighted. Interviews on making were based on recollections of recent projects with the employees involved, the uses of resulting artifacts in the education of Blind or visually impaired children, after 
which we invited the practitioners to reflect on what went well or wrong, followed by questions on their opinions about digital fabrication and how likely they would continue or the help they would need to do so. Interviews complement both the observations and the analysis work, as they shed light on how professionals think about their practices, how they explain them, and how research can be useful to practice-as they also shared their uncertainties and asked for the researcher's opinions on their practices.

Table 1. Study participants by professional occupations. We do not describe individuals to ensure anonymity.

\begin{tabular}{|c|c|c|c|}
\hline Group & Role & Professional Experience & Data \\
\hline Transcribers & $\begin{array}{l}\text { Adapt documents (braille, enlarged characters, adapted graph- } \\
\text { ics) }\end{array}$ & $\begin{array}{l}\text { From early-career ( }<2 \text { years) to ex- } \\
\text { pert (10+ years) }\end{array}$ & $\begin{array}{l}\text { Interviews } \quad(9), \quad \text { observations, } \\
\text { project documentation, source files }\end{array}$ \\
\hline $\begin{array}{l}\text { Special education teachers } \\
\& \text { School librarian }\end{array}$ & $\begin{array}{l}\text { Teach children in inclusive classrooms punctually or teach } \\
\text { small groups in special education classrooms }\end{array}$ & $\begin{array}{l}\text { From advanced ( } 5+\text { years }) \text { to Expert } \\
(10+\text { years })\end{array}$ & $\begin{array}{l}\text { Interviews }(9), \quad \text { observations, } \\
\text { project documentation }\end{array}$ \\
\hline Educators & $\begin{array}{l}\text { Assist special education teachers, develop group projects to } \\
\text { help children develop social skills }\end{array}$ & $\begin{array}{l}\text { From novice }(<2 \text { years }) \text { to Expert } \\
(10+\text { years })\end{array}$ & Interviews (3), observations \\
\hline $\begin{array}{l}\text { Locomotion and Mobility } \\
\text { Therapist }\end{array}$ & $\begin{array}{l}\text { Develop cognitive and practical spatial skills, teach the use } \\
\text { of white cane or orientation devices such as GPS, prepare } \\
\text { itineraries needed by teenagers and young adults, audit urban } \\
\text { or rural accessibility }\end{array}$ & Advanced ( $5+$ years) & Interviews (4), Observations \\
\hline Occupational Therapist & $\begin{array}{l}\text { Develop independent living skills, adapt objects for everyday } \\
\text { use including assistive technologies }\end{array}$ & $\begin{array}{l}\text { From early-career }(<2 \text { years }) \text { to ex- } \\
\text { pert }(10+\text { years })\end{array}$ & Interviews (3), Observations \\
\hline $\begin{array}{l}\text { Other Therapists (speech, } \\
\text { low-vision, psychomotor) }\end{array}$ & $\begin{array}{l}\text { Develop communication, oral and motor-speech coordination; } \\
\text { Develop efficient use of visual abilities for orientation, reading, } \\
\text { etc; Develop children motor skills (mobility, balance, posture, } \\
\text { orientation...) }\end{array}$ & $\begin{array}{l}\text { From advanced ( } 5 \text { years) to expert } \\
(10+\text { years })\end{array}$ & Interviews (3), Observations \\
\hline IT services & $\begin{array}{l}\text { Choose and maintain assistive technologies needed by stu- } \\
\text { dents, support research projects, choose professionals' soft- } \\
\text { ware and maintain their workstations, adapt workstations in } \\
\text { local organisations }\end{array}$ & $\begin{array}{l}\text { From early-career }(<2 \text { years) to ad- } \\
\text { vanced ( } 5+\text { years })\end{array}$ & Interviews (4), observations \\
\hline
\end{tabular}

We also collected 50 projects made using digital fabrication, which employees of AdaptSchool designed or co-designed between 2013 and 2020. We refer to these as projects as each might have been produced several times, iterated on but only one version is used, and might contain several objects (e.g., construction kit). We identified the projects through our observations, interviews, and the documentation produced by employees. All data excerpts were translated into English by the field researcher.

We did not collect quantitative data such as time spent using ideation software or digital fabrication tools. Participants found quantitative data collection as invasive or unrepresentative of their work. We believe that pushing against quantitative research approaches reflects a broader conflict around managerial approaches of health and education relying on data they find unrepresentative of their practices or harmful. We however generated quantitative insights during our analysis, such as the number of projects built with a given tools, when during the year projects were envisioned, designed or produced to analyse our qualitative data, as described in section 3.4.2.

\subsection{Ethics}

At the time most of the field study and interviews were conducted (2014-2018), approval by an ethics committee was not required by our university. We thus established our own ethical vetting process, consistent with approaches developed for participatory design [19, 49]. We commonly established a set of ethical principles (e.g., participation of the researcher to professional tasks consistent with her skills, open source design), as well as a process to report and cross-check findings with the people interviewed. We chose to report interview extracts without specifying more than the professional role of the person interviewed. Otherwise, it would have been possible to identify individual participants, as this is a small organization which could be deanonymized with some research. Later interviews received research ethics approval from the Cross Schools Research Ethics Committee (C-REC) of University of Sussex, under the reference ER/ETB20/8. This ethics board does not grant retrospective ethics approval. 


\subsection{Data Analysis}

We had initially organised the data by projects made by participants and coded it inductively, focusing on themes such as design characteristics of the projects, tools use for design (in ideation, modelling tools, fabrication), uses in teaching, the role of the making and professional community and of personal interests. We used a Qualitative Data Analysis (QDA) software (Nvivo). However, analysing data this way proved difficult: projects are negotiations between educational and making practices, which overlap and impact each other. We could not use QDA software to represent and explore these dynamics. We also noticed during coding that the codes and themes developed were similar to the components of Engeström's [14] Activity System Model (described in section 3.4.1). Moreover, we wanted to write an account that could be useful to practitioners. Participants in our study emphasised the contradictions they encountered working with digital fabrication tools. Contradictions are another core concept in Engeström's work, which consolidated our choice to turn to Activity Theory, specifically Activity System Models, as a theoretical background and empirical tool for our analysis, instead of theoretically flexible approaches such as Grounded Theory or thematic analysis.

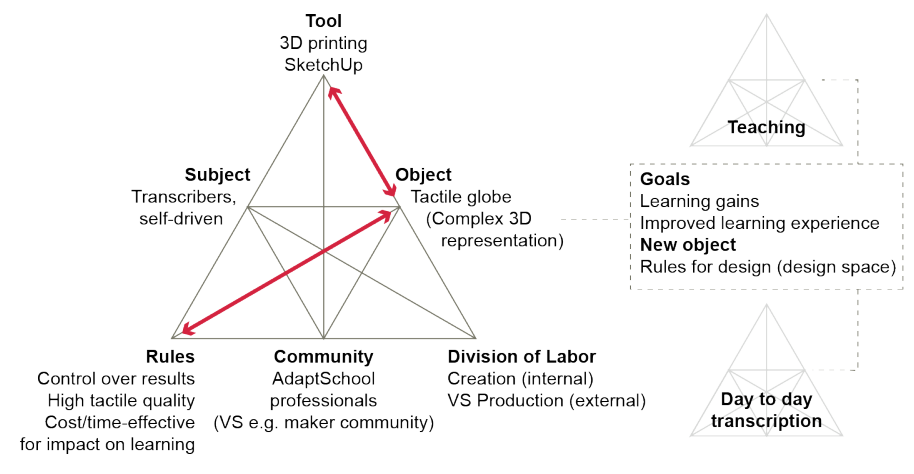

Step 1: Representing projects as activity systems, identifying contradictions (here in red, between tools and rules of practice) and the other activity systems they interact with. This is developed in the 3D printing section.

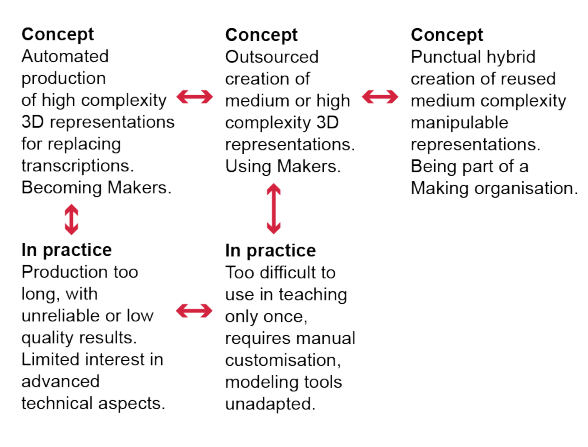

Step 2: Reconstructing how several projects contributed to a larger activity system (e.g., 3D printing for learning gains)

\begin{tabular}{|c|c|c|c|c|c|}
\hline $\begin{array}{l}\text { 1: Questioning } \\
\text { Could digital fabrication } \\
\text { ease or improve teaching } \\
\text { and/or or automate } \\
\text { transcriptions? }\end{array}$ & $\begin{array}{l}\text { 2: Historical } \\
\text { and empirical analysis } \\
\text { Which existing objects could } \\
\text { be replaced or made more } \\
\text { efficiently? Which existing } \\
\text { modeling tools used? }\end{array}$ & $\begin{array}{l}\text { 3: Modeling the new solution } \\
\text { 4: Examining new model } \\
\text { Broad range of experiments with laser cutting, } \\
\text { 3D printing and prototyping electronic platforms, } \\
\text { tested with professionals and students. } \\
\text { Acquisition of a 3D printer. Active documentation. }\end{array}$ & $\begin{array}{l}\text { 5: Implementing } \\
\text { Overall agreement } \\
\text { between professionals } \\
\text { over use and routinisation. } \\
\text { Punctual conflicts on } \\
\text { cost-effectiveness }\end{array}$ & $\begin{array}{l}\text { 6: Reflection } \\
\text { Formalisation through } \\
\text { professional guidance } \\
\text { for comments }\end{array}$ & $\begin{array}{l}\text { 7: Consolidating } \\
\text { Demands for } \\
\text { professionalisation, } \\
\text { increased financial } \\
\text { support (ongoing) }\end{array}$ \\
\hline
\end{tabular}

Step 3: Representing the entire expansive learning cycle.

Fig. 2. This figure presents excerpts from the data analysis process, based on the methodology outlined in [13]. Step 1 describes a contradiction (red arrows) between the rules guiding participants' perception of what a 3D tactile globe should be and the experience of using 3D printing tools. Step 2 shows the progressive changes in the perceptions of 3D printing. Step 3 shows the outline in the changes in practice, which we discuss in more details in the next sections.

3.4.1 Activity System Model. The Engeström's activity system model [14] is a tool for empirical analysis [8]. This model is rooted in activity theory research, first developed by Russian psychologists in the first half of the 20th century [39,60]. Of particular importance to HCI, activity theory emphasizes the role of tools as mediating artifacts between two components of the activity, human subjects and the world objects: highlighting that people "act through technology, rather than interact with it" [8]. In our study, this entails turning away from what digital fabrication tools might be used 
to produce; instead exploring how participants used digital fabrication tools not only to define what they can build but also how their practices would evolve.

The activity system model takes this further by introducing the community as an additional component: subjects rarely act alone, they are always enmeshed in various groups organised around goals, in this case accessible education. Communities impact activity through rules such as design standards and because they define the division of labor, who becomes responsible for a given task, making this approach particularly relevant for studies of work. Engeström developed the activity system model to explain changes in organisations. He emphasised that contradictions and breakdowns, either internal to an activity or between activities, drive the emergence of new objects and goals which ultimately changes work [13]. Trying to understand or resolve these contradictions is a learning process, ultimately leading to a consolidated new set of practices. This is what Engeström terms expansive learning cycles [14] although it also means that some practices are abandoned [16].

3.4.2 Data Reduction and Writing. Qualitative analyses often rely on a progressive process of data reduction. It is an essential step given the quantity of data involved (2000 pages of notes and transcripts along with collected documents). We used the activity system model to tag data across sources (interviews, observations, documents) as they pertained to the projects collected. We then wrote-up projects as a timeline of linked activity systems (Figure 2, Step 1. An excerpt of the timeline is also available in Supplementary Material). Once we could compare projects, we focused on identifying factors shaping practices, which we confirmed with the participants. In other words, we looked at how several projects contributed to a larger activity system the organisation, through which our participants defined what digital fabrication could or should be used for (Figure 2, Step 2).

We take the introduction of each digital fabrication tool as the initial questioning of practices (first step of the expansive learning cycle). Employees of AdaptSchool started using digital fabrication tools in three waves: laser cutters in late 2013, 3D printing in Spring 2015 (on Fused Deposition Modeling printers) and electronics prototyping platforms in late 2015. They started using laser cutting independently after they became aware through personal and professional networks of a nearby for-profit maker space, which also owned 3D printers. Two researchers respectively introduced 3D printing and electronics prototyping platforms and supported their use through collaborations on participantsdefined projects for four years and one year respectively. Onsite IT services also provided support with verifying files, demonstrating tools or explaining the technical issues encountered.

We then describe the projects through which our participants iteratively analysed, experimented and reflected on what each tool could be used (phases 2-4 - illustrated in Figure 2, Step 3). To write our findings, we first highlight the contradiction(s) faced; we describe the pedagogical needs identified and the factors impacting creation of new projects and production; we then discuss the components of the activity system and mediating factors at play, and where relevant, how they compare to the literature. This outlines 1) changes in practice and, 2) the resulting design space developed by professionals i.e. "a conceptual space, which encompasses the creativity constraints that govern what the outcome of the design process might (and might not) be" [1, p. 456]. In the next section, we discuss professionals' ongoing attempts to legitimate and share their practices with other organisations (phases 5-6: the expansive learning cycle is still to be completed). 

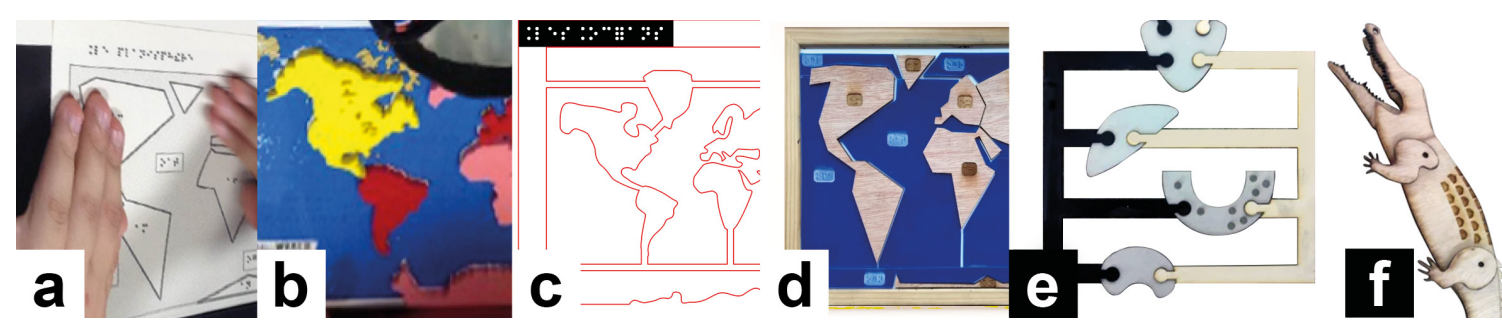

Fig. 3. Cognitive benefits: [a] Raised-line drawing and [b] puzzles as accessible tactile media predate digital fabrication. Puzzle manipulation likely helps with understanding individual shapes and their relations. They can easily be laser cut ([c] source file for a world map puzzle with removable oceans) and adapted in complexity, as in the [d] world map puzzle iteration by transcribers, fitted with magnets for easier manipulation and storage. Similar principles can be applied to diagrams of complex systems such as [e] the circulatory system diagram using colors and textures and colors for differentiating between significant parts. Beyond puzzles, articulated or movable tactile images such as [f] this crocodile draws attention to specific details (here on how they walk and swim with articulated legs.

\section{LASER CUTTING: FROM TACTILE OR MOVABLE PICTURES AND PUZZLES TO COMPLEX 3D REPRESENTATIONS}

\subsection{Contradiction}

While previous research and popular media framed on 3D printing as a digital fabrication tool of choice for DIY-ATs and on the accessible media, participants focused on laser cutting from early on. This is due to: (1) its large range of pedagogic applications, from 2D to 3D representations and school accessories, as well as the variety of materials and textures it offers; (2) the flexibility of modelling tools, their previous use for tactile graphics, and their integration with other craft practices; (3) the rapid and reliable production process. It remained a tool of choice, although it often necessitates expert knowledge of making accessible media to meet teaching standards and it sometimes is considered too expensive by the AdaptSchool's managers.

\subsection{Description}

The most immediate application for laser cutting is the creation of adapted 2D tactile representations of various complexity, with different materials and sometimes movable parts. They are designed with or for teachers and the school librarian, educators, or therapists. Transcribers' first project was a set of tactile symbols. Then in March 2015, a special education teacher asked the researcher for a map of oceans for primary school children, an adapted version of a puzzle of continents she used. It was too complex, but transcribers further iterated on this map in 2017 (Fig. 3b-d). Teachers perceive these puzzles beneficial to shape recognition, compared to tactile drawings, likely because it allows perceiving their outline at once [34].

Special education teacher: "Puzzles are interesting because they allow for sensing both the positive and the negative space, and it forces us to define that negative space. For the world map for instance, we don't mark the border between oceans on paper, but we can do that with the puzzle (2015). Educator: "I think what's interesting is the constraints, having to think about what detail or movement is relevant to what you want to describe. (2017)

Complex diagrams or schema similarly benefit from the richness of materials and the constraint of designing clearly separable parts. Take for instance the diagram of the circulatory system (August 2018, Figure 3-e). From the teachers' perspective, it is on the one hand more useful than a tactile drawing, as following each line to an organ requires 
reconstructing that arteries are connected, which is more clearly conveyed when they come as a single piece. On the other, the principle illustrated does not require a 3D representation, which would introduce more complexity. Intermediate representations, between tactile drawings and 3D objects, further allow to drawing attention to a given feature (Fig. 3-f).
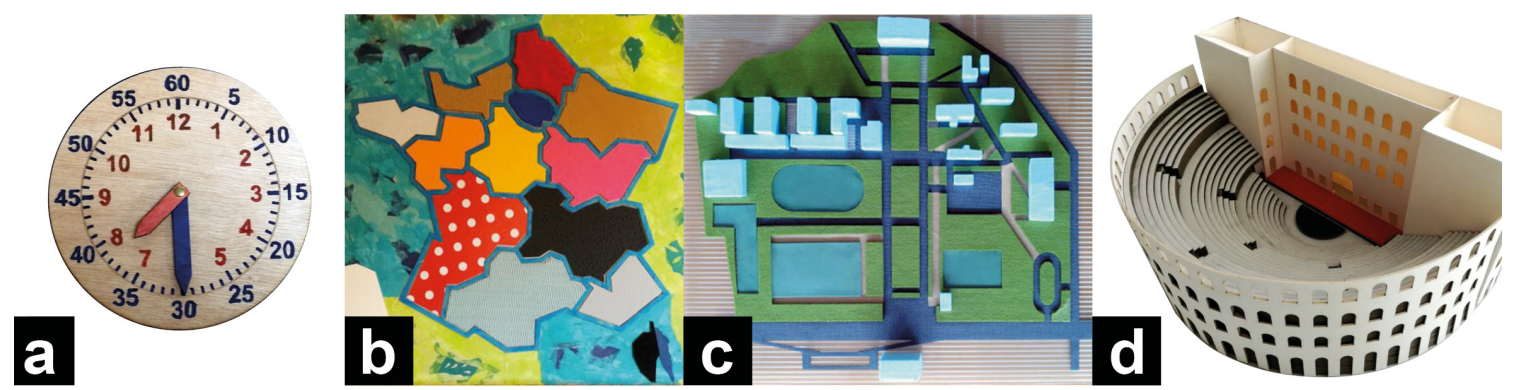

Fig. 4. Rich tactile experiences: [a] multimodal clock face with laser engraved enlarged numbers and marks. Made of plywood and handpainted with contrasting colors; [b] Map of France and its region using different fabrics as textures; [c] 2.5D map of a school campus using plywood, felt and plexiglas; [d] 3D scaled model of an amphitheater made of cardboard.

Beyond cognitive considerations, transcribers intently collect and curate a range of materials that can be laser cut to provide rich and enjoyable tactile experiences (Fig. 4). These representations rarely replace the day to day production of tactile graphics using specialised tools (e.g., raised line drawings - Fig. 3-a). Rather they replace the representations of key concepts teachers find especially difficult to explain, and add to employees' workload or to functioning costs. Only transcribers' production of school accessories aims at lowering costs. For instance, they created their first laser cut teaching aid, a metric conversion table in 2016 (Fig. 1-a). These tables are widely used in primary and secondary school, are difficult to adapt using a braille printer or raised line drawings. Teachers also perceive them as an ergonomic gain for children who can more easily manipulate numbers and do not have to adapt to the variety of ways tables would be presented. In August and September 2017, transcribers started making laser cut and engraved rulers, squares and protractors with enlarged and hand-painted or braille labels (1-a). They are less expensive to make than to buy, although this cost estimation does not factor in employee's time.

The creation of 2D representations and tools used builds upon transcribers' and teachers' previous knowledge with making tactile graphics. They traditionally used Microsoft Word drawing tools, which they found to resemble those of Inkscape. Two dimensional puzzles or movable pictures simplify the design of attachments: paper fasteners (Figs. 3-f, 4-a) and puzzle shapes are highly versatile. The use of laser cutting for 3D representations is far less expected. Beyond the advantages of using multiple materials, it affords a high and direct level of control to transcribers when they create new model. Consider the roman amphitheater (Fig. 4-d). Made of cardboard and paper, it leverages the properties of the materials: the stairs are created by the thickness of layered cardboard pieces; the curved wall uses flexible cardboard. This approach allowed them to make rough prototypes by hand that could be immediately tested and changed. However, it means it is more difficult to outsource the creation of new models. Disability professionals can envision what they need but their accumulated knowledge and preferences are hard to convey. For instance, the world map puzzle (Fig. 3-b-d) created by the field researcher in 2015, despite precise instructions by the special education teacher, did not meet needs. Transcribers shared their own iteration with another organisation, who made their own version, for instance having continents in different colors or changing the complexity of the continents' outline. 
The successful adoption of the laser cutter further depends on the specificity of the production process, which is entirely undertaken by transcribers, although they are sometimes joined by other employees for observations. While laser cutters are more expensive, they also are more rapid than 3D printing for accessible representations. Laser engraving takes longer and is carefully rationed: for instance, transcribers may choose to add braille labels afterwards instead of engraving them. It rarely requires post-production modifications, and hands-on finishes, such as painting and assembly require generic tools (glue, paints etc). Transcribers also perceive laser cutters are dependent and reliable. As they can only be used in a maker space (they require a significant safety infrastructure), the costs include technical assistance. Taken together, it means transcribers feel confident they can estimate the time necessary for a given project.

\subsection{Discussion}

The tools involved in a project produced with laser cutters allow participants (subjects) to build upon existing skills and transcription standards they use day-to-day for other accessible documents, as well as handicrafts. This partly explains why laser cutters were their tool of preference, including for $2.5 \mathrm{D}$ or 3D objects (e.g., 2.5D maps, moving pictures $[28,36,47])$ which previous research focused on 3D printing. Beyond the impact of tools on the design process, the range of materials available for laser cutting provides a richer tactile experience, which professionals identified as an important concern (rule) given the resources necessary for laser cuting projects. Moreover, laser cut and engraved objects are those that circulated the most within transcribers' professional community, and these practices are firmly rooted in this group of professionals as they enable, not automation, but customisation and remix that proved difficult in 3D printing [42]. However, the availability of these new tools has not contributed to a change in the division of labor or a community of makers. If anything special education teachers appear less likely to create material using the laser cutter than creating raised line drawings. By contrast with transcribers, they do not have access to a laser cutter on site and do not have justifications and dedicated time to go to a maker space, likely reinforcing the separation between their activities. The design of representations results from negotiations between education professionals from all groups, and even after six years is not formalised, let alone standardised.

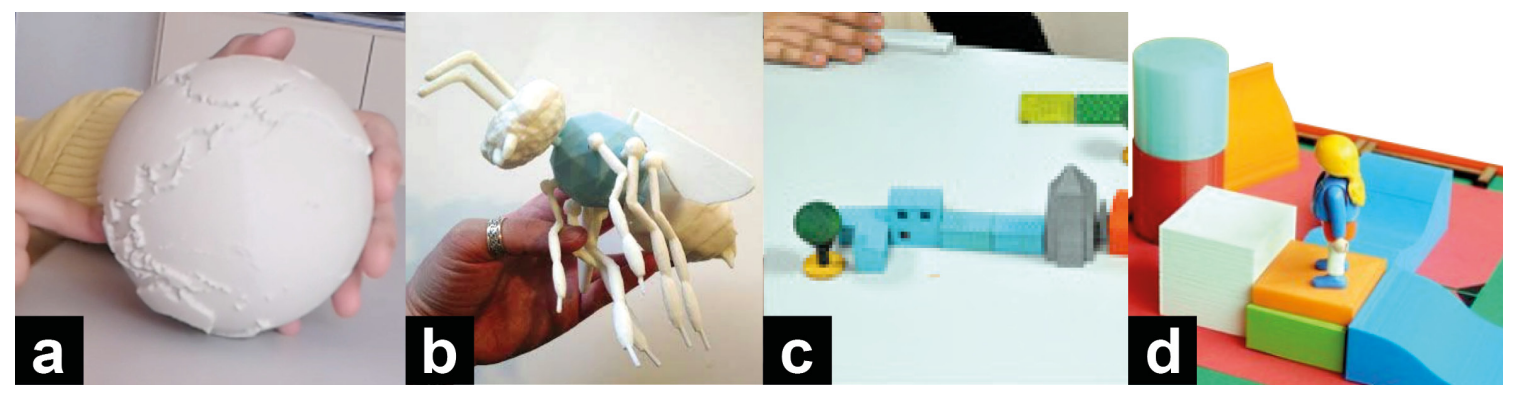

Fig. 5. High complexity 3D models ([a] a globe from Thingiverse, [b] a custom bee puzzle) are not agreeable to touch and rarely used. They also are long to print. We instead envisioned silicon molds or thermoforming matrices [45], but they deteriorate rapidly and would have to be painted by hand. Inspired by globe papercrafts, we recently realised we could create a sphere out of laser cut and engraved leather. Medium complexity 3D models could be used for working flexibly on spatial relations between elements (such as features of cities in [c]) but need to be used often (e.g., [d] scaled model of the gymnastics room used in psychomotor therapy). 


\section{3D PRINTING: FROM COMPLEX 3D REPRESENTATIONS TO MANIPULATIVES}

\subsection{Contradiction}

Despite sustained support by academic partners, eagerness on the part of transcribers to learn more about 3D modelling and printing and the availability of a 3D printer on site from year four, it is far less used than laser cutting. This is due to: (1) its limited usefulness in pedagogy; (2) the difficulty to adapt models made by others, modelling software used too rarely to be appropriated but it also did not offer the kind of expert direct manipulation that made laser cutting successful; (3) the length of production, defaults in the finished print and post production labor. Although transcribers continue using 3D printers, they have developed fewer projects and the creation of new models is even less collaborative than for laser cutting.

\subsection{Description}

Complex 3D representations appears to be a forward use of 3D printing [21,46], and a teacher requested early on to print a tactile globe found online. More broadly, teachers believe that: "Like $2 D$ lets you focus on relationships between parts, 3D gives you access to imperceptible features or phenomena, either because it's too big, too small, an inside mechanism or not a solid, or you want to explain how a section drawing but cannot cut the object it represents in two" (special education teacher, 2017). But they were rare, due to the time necessary for exploring and understanding them, and the difficulty for teachers to envision the simplifications needed to accommodate children with different cognitive abilities and experience in tactile reading. Later attempts include: an improved tactile globe from February to April 2017 (Fig. 1-d); a scaled-up model of a bee that could be disassembled for the yearly primary school field-trip in May and June 2017 (Fig. 5). But these were designed by the field researcher.

In the words of an experienced transcriber: "3D printing looks great but I already know what I can do with laser cutting, and I'm not so sure about 3D printing" (2014). "Seeing [the student] touching the globe, it's pretty evident the texture is not right [...] you don't want to give them a negative tactile experience, because that could impact their confidence" (2015). "With consumer-grade 3D printing it still seems to me we're very much limited to representing really large or really small objects at a different scale, what we need goes far beyond 3D printers' capabilities" (2020).

Medium complexity 3D representations, the combination of basic geometric volumes, are more common. They are useful as manipulatives, physical objects enabling students to interact with a concept, often in mathematics [41]. For instance, a special education teachers asked for simplified scaled models of houses, churches and other elements of urban environments for primary school geography lessons (Fig. 5-c), in April 2016. Along with these 3D printed manipulatives, the teacher used miniature toys familiar to children (e.g., toy cars). The teacher found 3D printed manipulatives required too much time for preliminary exploration before the core activity, compared to toys or the oral description of concepts. She suggested the lack of realism impedes both understanding and the learning experience, voiding potential benefits for engagement.

Therapists or other employees' focusing on independent living skills have a different rationale, as they use the same manipulatives or 2.5D maps regularly. For instance, from the Fall of 2015 to the late Spring of 2016, the transcribing team made a small scale model of the gymnastics room used by the psychomotor therapist.The manipulable small scale model aims at developing spatial orientation and manipulation of spatial concepts. It can for instance be used to mirror the organization of the room, to replay an exercise or to explain spatial relations between the toys (Fig. 5-d). 
Transcribers made other, similar sets of manipulatives, for instance for classrooms, and printed in some occasions simple landmarks for 2.5D maps.

We now turn to constraints with creating new models. For projects requiring low complexity 3D elements, such as 2.5D maps with cubic buildings (e.g., Fig. 4-c), current 3D modelling tools are sometimes less efficient than alternatives such as crafted foam. When working on the material, transcribers can directly perceive and adjust height for improving contrast. More broadly, they still find 3D modelling tools (in this case, SketchUp) difficult. Most of these projects only require basic features (creating volumes, combining or subtracting them, extruding a shape). However, time spent modelling is scattered over half-day or full day sessions set apart for digital fabrication over several months, preventing the consolidation of their expertise. 3D modelling tools hence often evoke negative feelings, requiring significant self-drive for persisting. In the words of a transcriber: "I have forgotten everything since last time, it's tiresome, I don't have the time to practice," and after another day of practice "manipulating [the objects in SketchUp] is still a bit too complicated to my taste..." (2016).

To overcome difficulties with using 3D modelling software, the field researcher and a mixed group of professionals experimented with a handheld consumer-grade 3D scanner from August 2015 and March 2016. The results were largely inconclusive as models required major edits to be tactily legible and enjoyable when printed. This informed the later design of the three dimensional bee (Fig. 5-b), which was in part sculpted in self-hardening modelling clay. This requires skills akin to sculpture that transcribers perceive as beyond their expertise. The field researcher and the IT support team further demonstrated how to use 123Design (discontinued in 2017), TinkerCAD and Blender, all commonly used in maker communities. While document makers were eager to learn, the lack of regular enough use described above limited more advanced use of 3D modelling software. Regardless, they feel proficient for the low and medium complexity representations they $3 \mathrm{D}$ print.

But even when complex 3D models are useful and can be sculpted, 3D printing might fall short of promises to share and reproduce accessible media at the push of a button. We could not scan the bee part successfully; even if we had, the teacher wanted this representation to provide a lot more qualitative details, since students would spend a fair amount of time focused on it. Textures such as fabric were glued to parts of the model and others were painted by hand, a manual labor that cannot currently be automated. Furthermore, technical issues common for objects produced with Fusion Deposition Modelling hobbyist printers, such as deformations, gaps, or burns hindered understanding as pupils took them as hint of what the object represented.

Beyond quality issues, the low speed and size of consumer-grade 3D printers create additional barriers. In 2018, AdaptSchool acquired a consumer-grade 3D printer, which was placed with his braille printers and other specialised equipment, hoping it would elicit new projects and make 3D printing easier. Large prints such as the tactile globe can take up to $24 \mathrm{~h}$ total. As the process requires monitoring, transcribers would have to break it down in smaller pieces and have the school 3D printer running through the day which is not convenient, or outsourced its production which is expensive. Despite the availability of an approved and tested model, it was not printed again. Meanwhile, printing several small models at the same time means that any error compromises the entire production. They therefore prefer going to a makerspace nevertheless to launch several prints at the same time, which makes monitoring easier, in addition to onsite support. Finally, we attempted to use selective laser sintering (SLS) and stereolithography (SLA) 3D printers. While professionals found the texture of SLA printed objects more adequate, these prints were only available commercially and their price prohibitive. Moreover, it remains that 3D printed textures are limited compared to the range of materials available for laser cutters. 


\subsection{Discussion}

While professionals (subjects) had high hopes for the potential of 3D printers and attempted repeatedly to integrate them to their practices, they are even less integrated in practices. They do not afford the same design flexibility than laser cutters, Moreover, 3D representations are not needed as often as the 2D or 2.5D representations that made laser cutting successful, nor were they of good enough quality to improve the learning experience without hand modifications and finishes to ensure a positive tactile experience. This was well illustrated by how teachers chose to use commercially available toys instead. This compounded with the difficulties experienced using 3D modelling tools which differ from daily used tools and the design standards of tactile graphics; and with the lesser reliability and speed of the production process or the costs of external production. While onsite availability of a printer could afford integration in everyday activities of the organisation monitoring lengthy prints did not fit existing schedules. That this tool remained in use can be explained by transcribers self-motivation and personal interest in making and continuous support by academic partners and IT services and its utility in some representations for developing locomotion and mobility skills (see [28] for similar examples in other contexts). Given these limitations, the professional community around this tool is far less developed than for laser cutting. Furthermore, while these disability professionals (in particular a transcriber) have used maker spaces repeatedly, they do not get more actively involved in the local or larger maker community and are hence unlikely to receive volunteer help. This might be further compromised by the craft and handmade aspects of the objects made, which tend to be less valued in maker spaces [12].
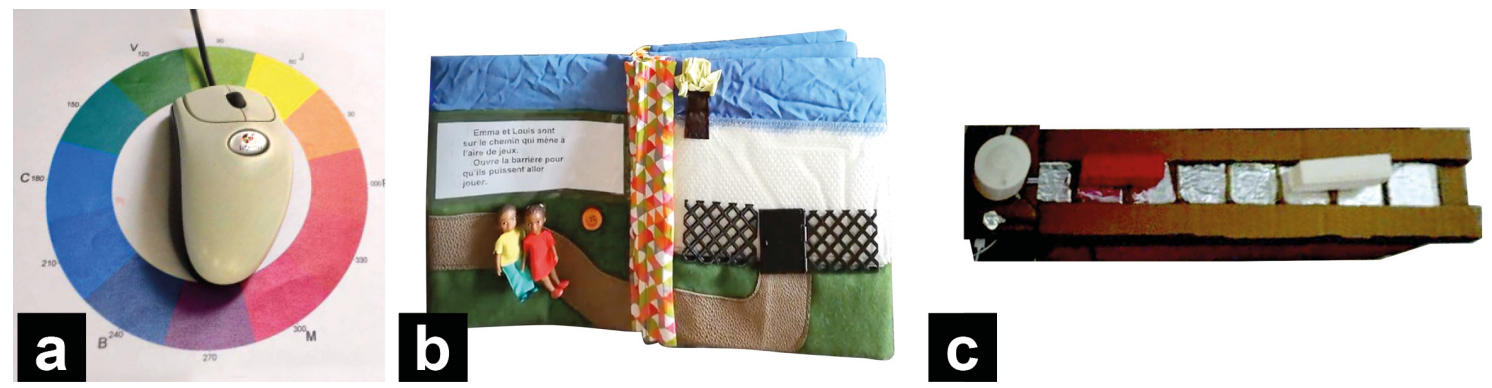

Fig. 6. Examples of interactive projects developed during hackathons: [a] a simple sensory substitution device, replacing colors with non-speech sounds; [b] spread from a sewn interactive book including small objects and recorded sounds; [c] a timeline made of cardboard and aluminium foil controlled by a Bare Conductive controller for exploring historical events and periods represented as $3 \mathrm{D}$ printed blocks, with spoken description of different complexity (changed using the knob).

\section{DIY INTERACTIVE PROJECTS}

\subsection{Contradiction}

Electronic prototyping platforms to make interactive assistive technologies are widely available and appear usable by beginners [38]. But we know there are many barriers to overcome to even consider oneself a beginner [12, p. 108] and participants have no previous experience in this domain that could help this process. Yet, since an academic partner introduced these platforms in 2015, professionals have envisioned many applications using sounds to improve the learning experience. However, they rely upon teachers in local universities assigning these projects in undergraduate courses; and the projects are often unfinished and generally can not be repaired when an issue arise. Electronic 
prototyping platforms continue being use because the resulting projects serve community-building, engagement and speculative purposes.

\subsection{Description:}

In 2013-2014, an occupational therapist emphasised on replacing costly assistive technologies such as whiteboard enlargers with mobile consumer technology (namely a tablet and a bluetooth camera). She was also monitoring accessible technology innovations, to propose adapted combination of apps and techniques for each child receiving services at AdaptSchool, and sharing her findings. This was gradually taken over by the IT services. Although the whiteboard camera system was never deployed, this illustrates the individual and AdaptSchool's will to invest in appropriating technologies, regardless of actual outcomes.

In 2015, a second field-researcher introduced electronic prototyping platforms (Makey-Makey, Bare Conductive and LilyPad) and supported the participants in creating their own interactive learning materials. In addition, the local academic partners organised a first 'hackathon'. Hackathons are generally defined as short events for collocated collaborative programming to address a given problem [58]. In this case, the goal was to create physical and interactive prototypes over a few months based on a brief and with the feedback of the AdaptSchool's employees. The hackathon was publicised by the local maker space, but there were no volunteers. Instead, academic partners involved students from the computer sciences track at the local university to work on these projects for a course on making. Five cohorts were involved from 2016 to 2020 . Every year, four to eight prototypes are presented by students to the local community and industry sponsors as well as documented online for their wider professional network and potential industry partners. All types of employees working with children (see Table 1) have submitted briefs.

The interactive projects developed by students during the hackathons belong to the following categories: interactive games using the audio modality, educational or not; objects or representations with audio labels; sensory substitution devices, such as a tool substituting colors or heights with sounds; simulated environments to develop mobility skills; and in one case, an obstacle detector for visually impaired wheelchair users (Fig. 6). Few parts for these prototypes were 3D printed. Students most often used a combination of crafts, laser cutting and real objects at the demand of disability professionals, like the projects previously described. Disability professionals also lead sound design, largely preferring self-recorded sounds and voices. Most of these projects were designed for both visually impaired and Blind children. The main motivation for their design, and the main criteria against which disability professional evaluated their usefulness, was to increase children's engagement in learning. Interactivity was used to provide them an opportunity to explore learning materials independently, increase their opportunities for learning in informal settings such as their home and helping children with cognitive disabilities explore situations they find too stressful.

Some of these objects, the interactive books, an interactive timeline and the sensory substitution devices continued being used for several months, or until they stopped working. This is despite the time for set-up or recurrent technical glitches. Teachers and therapists explained this by the positive impact on students' engagement. They could be adapted to new topics or used by several groups of children. However, only the interactive books were maintained over several years: the first was produced during the hackathon of 2016, finished a year later and is still in use. It used a Lilypad MP3 board, which transcribers learned to use, solder, and troubleshoot. They are however complex to make. For their latest book project, transcribers are planning to use a talking pen, despite disliking their audio quality. 


\subsection{Discussion}

Somewhat paradoxically, DIY interactive projects are successfully used in teaching practices because their design is outsourced to others who have the technical skills and professional interests, or in other words, it does not require to change the internal division of labor. But they often do not last because they can not be fully integrated in everyday practices of making educational material, neither their design nor maintenance. They never became a design tool through which disability professionals could build new objects, although they progressively became more able to describe potential technologies that may affect their profession in the future. The motivations (rules) for creating DIY interactive projects differ educational material with 3D printers or laser cutters, as they include this speculative dimension, in line with AdaptSchool's broader aims to be considered innovative. Then, he relative rarity of DIY interactive projects is also what makes them pedagogically useful: overall, they are used punctually to reinforce children's engagement and learning experience over more formal learning outcomes. They however require to build an educational community able to build these prototypes, which requires its own labor of maintenance and relies on the good will of individual professors.

\section{LEGITIMATING AND IMPLEMENTING NEW PRACTICES}

In the previous sections, we describe disability professionals' practices with digital fabrication tools. We further outline the design space they developed, the entangled and sometimes contradictory learning, creation and production constraints they worked through. We hint at conflicts between AdaptSchool's employees and management around costs and evaluating the actual value of these practices. In this section we turn to employee's work to fully implement digital fabrication in their practices and to spread their use in similar organisations: the latest steps in Engeström's [13] expansive learning cycle. We examine what practices they sought to legitimate, how and why.

\subsection{Contradictions}

Employees face multiple contradictions at the organisational level. Innovation and professional development on the topic of new technology is encouraged, in part to gain new funding stream through the provision of new services. Yet there is no coordinated management effort to ensure these aims are met. Moreover, these changes are made with no additional hires. It leaves to employees themselves to negotiate material resources project per project and shift priorities in the design of educational materials to make space for digital fabrication. Aspirations to innovate go beyond AdaptSchool. Multiple state funded projects enabled them to collaborate with academic partners. Other organisations even hired industrial designers for a short period. But a similar lack of coordination bars or limits their attempts at sharing, spreading and systematizing the practices they develop.

\subsection{Description}

AdaptSchool sometimes receive orders from local organisations (e.g., museums, scientific societies) for making accessible representations, mostly using digital fabrication. As these projects are paid for, transcribers can set time apart for their realisation. It secures them time to continue learning and making projects that do not come with their own sources of funding, or that are not school accessories and are not immediately needed. Ultimately, this could result in AdaptSchool fully recognizing digital fabrication and formally trained designers as necessary to the services provided.

To spread practices beyond AdaptSchool, transcribers argue for structured documentation and archival. They currently use online libraries of models (e.g., Thingiverse, Instructables) to share their work but find them limited and 
difficult to update regularly. Reflecting on the laser cut world maps (Fig. 3), which have been replicated and adapted by other professionals, transcribers and teachers described a documentation including source files, notes about production, pictures of the final object and a description of the pupil(s) with whom the design was tested, in addition to grade, subject and potentially, learning activities. Transcribers firmly describe this library as beyond their own professional responsibilities, and rather as a public service to be established at the national level extending the national digital library of tactile drawing to digital fabrication. Beyond the aim to better share the labor of creating materials, transcribers also described well maintained libraries as a means to improve their practices through empirical comparisons with others.

Transcribers have increasingly argued over the last three years that the current informality of practices with digital fabrication is unsustainable. They advocate for formal training, the official recognition of the time or labor resources needed, and even partially centralizing the production of models to reduce obstacles such as the unavailability of a laser cutter or reduce costs. They attribute the adoption of digital fabrication to strong personal interest, which does not easily translate to other organisations. This is despite ongoing informal exchange of expertise through professional mailing lists and meetings. For instance, a transcriber has written a short report with examples about laser cutting and published it on a professional blog in 2019 and invited friends working elsewhere to submit brief for the hackathons. But they feel they do not manage to reach or convince professionals outside of their personal network. Common understanding of digital fabrication as easy to self learn likely impact how much funding is available for training. Since 2017, the AdaptSchool proposes to lead professional training on the use of new technologies and digital fabrication, but could not get the necessary financial support.

The way transcribers, as the group of professionals most directly involved with digital fabrication tools, envision the lasting implementation of digital fabrication is neither local nor centralised. It is rooted in longstanding labor and professional practices recognising the importance of local expertise for rapidly adapting to learning needs, and the pooling of resources where it is not necessary to develop highly personalised learning materials. While they do not believe full automation is possible, professionals' sense of work ownership and expertise does not depend on controlling the entire digital fabrication process, but on being part of it.

\subsection{Discussion}

Despite the successful identification of a design space, digital fabrication tools are only partially legitimate and require significant shifts in employees' workloads and the organisation of labor. In response, transcribers and teachers have pushed towards the development national tools for appropriate documentation and archival. This is a way to legitimate the use of digital fabrication in this domain and supporting professional development and empirically grounded standards (rules). Previous research has seldom investigated the design of tools for supporting this development holistically. They describe how available models should align with the current national curriculum, which changes often. This strikes a blow to hopes for worldwide community, sharing models to replicate friction less. Furthermore, they clearly push against relying on maker-minded employees, instead pushing for the formal attribution of resources to making professionals: industrial designers.

\section{DISCUSSION}

Employees of an organisation providing educational support and services to visually impaired and Blind children experimented with a range of digital fabrication tools for seven years, expanding a design space for educational accessible media, and to a lesser extent educational and assistive mobility technologies. Our practice-driven research approach nuances the hopes about the impact of digital fabrication on accessibility. The availability of models to print 
does not necessarily enable cheaper and faster production; digital fabrication tools do not replace specialist equipment or the use of crafts; 3D representations are not so often useful in these formal educational context, and in any case 3D printing limits their quality; the low cost of digital fabrication tools does not directly determine their usefulness, and by focusing on issues with design tools we might overlook organisational solutions to the provision of DIY-ATs that we could support. In this discussion, we reflect back on the practices describe to identify new areas for research, using the activity system model as a lens. Although the study focused on accessibility, it can help us better understand under which conditions digital fabrication changes work in professions beyond engineering and design.

\subsection{From Tools to Objects: a Practices-Based Design Space}

Table 2. Overview of the design space. LC: Laser Cutting; 3DP: 3D Printing; C: crafting techniques; EPP: Electronics Prototyping Platforms; BL: Braille Labeller.

\begin{tabular}{|c|c|c|c|c|}
\hline Objects & Modelling tools & $\begin{array}{l}\text { Production } \\
\text { Tools }\end{array}$ & Design and production notes & Rationale for making \\
\hline Puzzles & Inkscape & LC & Use of contrasting textures and meaningful colors. & $\begin{array}{l}\text { Understanding how different parts of a complex } \\
\text { systems fit together. }\end{array}$ \\
\hline Tactile Graphics & Inkscape & LC, C, EPP & Use of interesting textures; Sometimes interactive. & Improving learning experience and engagement. \\
\hline School accessories & Inkscape & $\mathrm{LC}$ & $\begin{array}{l}\text { Multimodality (tactile and visual) and high contrast } \\
\text { are important }\end{array}$ & Replaces more expensive commercial alternatives. \\
\hline Teaching aids & Inkscape & $\mathrm{C}, \mathrm{LC}, \mathrm{BL}$ & $\begin{array}{l}\text { Multimodality (tactile and visual) and high contrast } \\
\text { are important; Using a BL can be faster than laser } \\
\text { engraving, but is not efficient if there is a large num- } \\
\text { ber of braille labels or positioning is complex; Could } \\
\text { potentially use interactivity. }\end{array}$ & $\begin{array}{l}\text { Improves learning ergonomics with expected } \\
\text { learning gains, replaces more expensive alternative. }\end{array}$ \\
\hline $\begin{array}{l}2.5 \mathrm{D} \text { representations } \\
\text { (tactile books, maps) }\end{array}$ & Inkscape & $\begin{array}{l}\text { C, LC, EPP, } \\
\text { Talking Pen, } \\
\text { 3DP (rare) }\end{array}$ & $\begin{array}{l}\text { Use of interesting textures and realistic colors } \\
\text { where possible; Sometimes interactive (generally, } \\
\text { use of recorded voices or sounds over generated } \\
\text { sound). }\end{array}$ & $\begin{array}{l}\text { Creating symbolic representations for developing } \\
\text { literacy; Ease understanding of complex environments. }\end{array}$ \\
\hline $\begin{array}{l}\text { Kits of Mid complexity } \\
\text { 3D representations }\end{array}$ & SketchUp & $3 \mathrm{DP}$ & $\begin{array}{l}\text { Using contrasted and usually bright colors for play- } \\
\text { fulness (realistic colors are difficult to achieve). }\end{array}$ & $\begin{array}{l}\text { Understanding children's own representations; } \\
\text { Helping children understand spatial relations between } \\
\text { different objects. }\end{array}$ \\
\hline $\begin{array}{l}\text { High complexity } \\
\text { 3D representations }\end{array}$ & $\begin{array}{l}\text { Blender, Inkscape, } \\
\text { manual (sculpting) }\end{array}$ & C, 3DP, LC & $\begin{array}{l}\text { Ideally there should be representations of multi- } \\
\text { ple degrees of complexity or it should be disas- } \\
\text { semblable for progressive exploration; Sometimes } \\
\text { made interactive. Generally, use of recorded voices } \\
\text { or sounds over generated sound. }\end{array}$ & $\begin{array}{l}\text { Mainly improving the learning experience and } \\
\text { motivation. Representing imperceptible phenomena } \\
\text { difficult to explain in 2D. Explaining the rationale for } \\
\text { section drawings. Used sparely. }\end{array}$ \\
\hline $\begin{array}{l}\text { Other Interactive } \\
\text { Prototypes }\end{array}$ & Inkscape & $\mathrm{C}, \mathrm{LC}, \mathrm{EPP}$ & $\begin{array}{l}\text { Generally, use of recorded voices or sounds over } \\
\text { generated sound. }\end{array}$ & $\begin{array}{l}\text { Mainly improving the learning experience and } \\
\text { motivation, through supporting independent access to } \\
\text { information and gamification. Used sparely. }\end{array}$ \\
\hline
\end{tabular}

Table 2 summarises the outcomes of digital fabrication practices we collected. Here, we reflect on implications for the design of accessible educational material as, with the exception of one prototype of a wheelchair obstacle detector, we have not observed any other types [5] of DIY-ATs such as accessories for assistive devices. As hands-on learning is a popular pedagogy [41], many of the projects collected could encourage collaboration between sighted and visually impaired children. Using digital fabrication aimed at making services less expensive, but producing accessible educational material in larger numbers could have the same effect. For instance, there exist Montessori tactile globes fairly close to teachers' design requirements. But education will not become accessible simply by making learning hands-on, and as we have seen sometimes the complex 3D representations praised for their educational value actually require significant cognitive efforts that are helped by vision, and end up not being used. The needs of disabled learners need to remain at the core of design. Following on collaboration, future HCI research might want to focus on developing more robust, easy to customise and self-contained ways to add an interactive audio overlay to representations when explored by several learners. 


\subsection{New Rules, New Tools: Flexibility from Modelling to Documentation}

With this new view of design constraints, or rules in the activity system model, what can we learn about designing new tools for this context? To address the difficulties when adapting 3D models to print, previous research has investigated various parametric (e.g., choosing within design parameters to generate a new model $[42,47]$ ) and direct modeling tools (e.g., with Lego [35]). None of these tools were available to the participants in our study but their approach to the design of complex representations and the repeated technical issues with 3D printing (section 5) suggest this approach might miss the mark. Even if we set aside the issue of tactile quality and privileging rich textures, laser cutting is adopted due to its flexibility and versatility. It both affords a more direct relationships between ideation and production through the ease of physical prototyping and builds on previous and daily-used techniques for producing accessible media while reminding of crafts such as sewing and origami. These flexible modelling tools appear more conducive to explorations. Future HCI research could investigate how to best support the documentation and expertise sharing possibilities described (section 7), for a collective and inter-organisations approach to digital fabrication.

\subsection{Subjects, Communities and the Division of Labor: Counterfactuals}

The hope digital fabrication would expand community participation in creating or adapting assistive technologies largely underpins the literature on DIY-ATs, even as many (e.g.,[30, 51]) have pointed to the barriers to overcome. In our study however, digital fabrication had only reinforced the central role of professional transcribers, who translated ideas or needs into new objects. To what extent is it specific to AdaptSchool and its division of labor? We offer some counterfactuals, based on observations and informal discussions at other disability organisations which have integrated digital fabrication to their practices in the country studied. For instance, one organisation did not include transcribers at all. Instead high school special education teachers made requests to external providers or contractors for a few, highly deliberated projects instead of broader material explorations. Another organisation sought public and foundation funding to open a maker space offering free and commercial making services, benefiting from the maker spaces' employees expertise. But overall, similarly to the AdaptSchool, most disability professionals did not develop the technical expertise to use digital fabrication tools autonomously, yet consider it as part of the practices of their organisations. Other countries rely on completely different communities and division of labor. We mentioned that in the United States, it appears an important share of braille transcribers are volunteers [9]. In other countries, adaptation may be done by teaching assistants with limited access to crucial technical and professional resources. In countries with more incentives to volunteer (for instance by securing extra-credits), disability services organisations might better manage to involve the general public in producing DIY-ATs, although involving a community of volunteers in itself requires resources, which instead could be invested in disability professionals. The introduction of digital fabrication tools is likely to have different organisational impact depending on the context, which should be investigated in future work.

We do not believe this undermines our argument for moving away from studies of digital fabrication separated from the labor structures in place to ensure inclusive education, including professional document transcription services. It also does not invalidate our argument for studying and supporting the creation and production of accessible media not at the very local or at a universalised level, but at intermediate levels appropriate to the context. Even if we hypothesised more automated and higher end 3D printers and advanced tools to help with modelling, they still would not be needed on a daily basis except if there were significant differences in teaching practices. In turn, as we shown, it means disability professionals find it difficult to develop or maintain their skills. Further, for parents or others who want to give children 
access to more representations, without the constraints of formal learning activities, crafts or found objects might be more appropriate than digital fabrication ${ }^{2}$.

Finally, counterfactuals can help us think about disability professionals' identities and how digital fabrication and making shape them. Regardless of their personal interest in crafts, we have not found professionals take on the identity of a 'maker. ${ }^{3}$ ' Regular professional use of a maker space does not seem to encourage personal use. To understand digital fabrication in work, we need to reconceptualise making as the activities of individual makers coming together and instead focus on how it can be appropriated by a professional collective.

\section{CONCLUSION AND PERSPECTIVES}

To understand how digital fabrication may impact the day-to-day provision of assistive technologies for the education of visually impaired children, we conducted a six year-long study with a French organisation providing educational services to this group. We drew on activity theory to describe and analyse the projects made during this time. We highlighted how uses of digital fabrication build on other techniques for making tactile media and argued future HCI research should primarily focus on supporting this adaptability and systems for knowledge sharing.

\section{ACKNOWLEDGMENTS}

We thank our research participants for sharing their expertise, in particular Nathalie Bedouin, Laurence Boulade and Grégoire Denis, as well as all the children involved in our fieldwork. Many thanks to Bess Williamson and Nolwenn Maudet for their feedback. This work was supported by ANR (Accessimap - ANR-14-CE17-0018; GESTURE ANR-16-CE33-0023).

\section{REFERENCES}

[1] Michael Mose Biskjaer, Peter Dalsgaard, and Kim Halskov. 2014. A Constraint-Based Understanding of Design Spaces. In Proceedings of the 2014 Conference on Designing Interactive Systems (Vancouver, BC, Canada) (DIS '14). Association for Computing Machinery, New York, NY, USA, 453-462. https://doi.org/10.1145/2598510.2598533

[2] Emeline Brulé and Gilles Bailly. 2018. Taking into Account Sensory Knowledge: The case of geo-techologies for children with visual impairments. In Proceedings of the 2018 CHI Conference on Human Factors in Computing Systems. ACM, New York, NY, USA, 1-14.

[3] Emeline Brulé, Gilles Bailly, Anke Brock, Annie Gentès, and Christophe Jouffrais. 2018. An exploratory study of the uses of a multisensory map-with visually impaired children. Multimodal Technologies and Interaction 2, 3 (2018), 36.

[4] Emeline Brule, Gilles Bailly, Anke Brock, Frédéric Valentin, Grégoire Denis, and Christophe Jouffrais. 2016. MapSense: multi-sensory interactive maps for children living with visual impairments. In Proceedings of the 2016 CHI Conference on Human Factors in Computing Systems. ACM, New York, NY, USA, 445-457.

[5] Erin Buehler, Stacy Branham, Abdullah Ali, Jeremy J Chang, Megan Kelly Hofmann, Amy Hurst, and Shaun K Kane. 2015. Sharing is caring: Assistive technology designs on thingiverse. In Proceedings of the 33rd Annual ACM Conference on Human Factors in Computing Systems. ACM, New York, NY, USA, 525-534.

[6] Erin Buehler, Niara Comrie, Megan Hofmann, Samantha McDonald, and Amy Hurst. 2016. Investigating the implications of 3D printing in special education. ACM Transactions on Accessible Computing (TACCESS) 8, 3 (2016), 1-28.

[7] Anna Cavender, Shari Trewin, and Vicki Hanson. 2014. Accessible writing guide. Sigaccess. https://www.sigaccess.org/welcome-to-sigaccess/ resources/accessible-writing-guide/

[8] Torkil Clemmensen, Victor Kaptelinin, and Bonnie Nardi. 2016. Making HCI theory work: an analysis of the use of activity theory in HCI research. Behaviour \& Information Technology 35, 8 (2016), 608-627.

[9] Anne L Corn and Robert S Wall. 2002. Training and availability of braille transcribers in the United States. Fournal of Visual Impairment \& Blindness 96, 4 (2002), 223-232.

\footnotetext{
${ }^{2}$ The work done by several non-profits goes in this direction. E.g.: www.pathstoliteracy.org/blog/tactile-books-very-young-children

${ }^{3} \mathrm{HCI}$ scholars (e.g. $\left.[17,18]\right)$ have long criticised a monolithic definition of makers and making as college educated and technology-oriented individuals. But this body of research usually remains focused on hobbyist activities, rather than digital fabrication in a professional context.
} 
[10] Daniel Cruz, Maria Luisa G Emmel, Mariana G Manzini, and Paulo V Braga Mendes. 2016. Assistive technology accessibility and abandonment: challenges for occupational therapists. The Open fournal of Occupational Therapy 4, 1 (2016), 10.

[11] Sarah R Davies. 2017. Hackerspaces: making the maker movement. John Wiley \& Sons.

[12] Christina Dunbar-Hester. 2019. Hacking Diversity: The Politics of Inclusion in Open Technology Cultures. Princeton University Press.

[13] Yrjö Engeström. 2001. Expansive learning at work: Toward an activity theoretical reconceptualization. Fournal of education and work 14, 1 (2001), 133-156.

[14] Yrjö Engeström. 2014. Learning by Expanding: An Activity-Theoretical Approach to Developmental Research (2 ed.). Cambridge University Press. https://doi.org/10.1017/CBO9781139814744

[15] Marie-Hélène Heitz Ferrand. 2017. L'imprimante 3D pour la scolarisation des élèves en situation de handicap: des expérimentations en classe. La nouvelle revue de l'adaptation et de la scolarisation 3 (2017), 301-316.

[16] Kirsten Foot and Carole Groleau. 2011. Contradictions, transitions, and materiality in organizing processes: An activity theory perspective. First Monday (2011).

[17] Sarah Fox. 2015. Feminist hackerspaces as sites for feminist design. In Proceedings of the 2015 ACM SIGCHI Conference on Creativity and Cognition. ACM, New York, NY, USA, 341-342.

[18] Sarah Fox, Rachel Rose Ulgado, and Daniela Rosner. 2015. Hacking Culture, Not Devices: Access and Recognition in Feminist Hackerspaces. In Proceedings of the 18th ACM Conference on Computer Supported Cooperative Work \& Social Computing (Vancouver, BC, Canada) (CSCW '15). Association for Computing Machinery, New York, NY, USA, 56-68. https://doi.org/10.1145/2675133.2675223

[19] Christopher Frauenberger, Marjo Rauhala, and Geraldine Fitzpatrick. 2017. In-action ethics. Interacting with Computers 29, 2 (2017), $220-236$.

[20] Morton Ann Gernsbacher. 2017. Editorial Perspective: The use of person-first language in scholarly writing may accentuate stigma. Journal of Child Psychology and Psychiatry 58, 7 (2017), 859-861. https://doi.org/10.1111/jcpp.12706 arXiv:https://onlinelibrary.wiley.com/doi/pdf/10.1111/jcpp.12706

[21] Uttara Ghodke, Lena Yusim, Sowmya Somanath, and Peter Coppin. 2019. The Cross-Sensory Globe: Participatory Design of a 3D Audio-Tactile Globe Prototype for Blind and Low-Vision Users to Learn Geography. In Proceedings of the 2019 on Designing Interactive Systems Conference (San Diego, CA, USA) (DIS '19). Association for Computing Machinery, New York, NY, USA, 399-412. https://doi.org/10.1145/3322276.3323686

[22] Stéphanie Giraud, Anke M Brock, Marc J-M Macé, and Christophe Jouffrais. 2017. Map learning with a 3D printed interactive small-scale model: Improvement of space and text memorization in visually impaired students. Frontiers in psychology 8 (2017), 930.

[23] Stéphanie Giraud, Philippe Truillet, Véronique Gaildrat, and Christophe Jouffrais. 2017. "DIY” Prototyping of Teaching Materials for Visually Impaired Children: Usage and Satisfaction of Professionals. In International Conference on Universal Access in Human-Computer Interaction. Springer, 515-524.

[24] Foad Hamidi. 2019. DIY Assistive Technology Prototyping Platforms: An International Perspective. IEEE Pervasive Computing 18, 4 (2019), $12-16$.

[25] Deanna Herst. 2019. Destandardizing Design? Learning from Critical Users. The Critical Makers Reader:(Un) learning Technology (2019), 206.

[26] Megan Hofmann, Jeffrey Harris, Scott E Hudson, and Jennifer Mankoff. 2016. Helping hands: Requirements for a prototyping methodology for upper-limb prosthetics users. In Proceedings of the 2016 CHI conference on human factors in computing systems. ACM, New York, NY, USA, 1769-1780.

[27] Megan Hofmann, Kristin Williams, Toni Kaplan, Stephanie Valencia, Gabriella Hann, Scott E Hudson, Jennifer Mankoff, and Patrick Carrington. 2019. " Occupational Therapy is Making" Clinical Rapid Prototyping and Digital Fabrication. In Proceedings of the 2019 CHI Conference on Human Factors in Computing Systems. Association for Computing Machinery, New York, NY, USA, 1-13.

[28] Leona Holloway, Kim Marriott, and Matthew Butler. 2018. Accessible maps for the blind: Comparing 3D printed models with tactile graphics. In Proceedings of the 2018 CHI Conference on Human Factors in Computing Systems. Association for Computing Machinery, New York, NY, USA, 1-13.

[29] Leona Holloway, Kim Marriott, Matthew Butler, and Alan Borning. 2019. Making Sense of Art: Access for Gallery Visitors with Vision Impairments. In Proceedings of the 2019 CHI Conference on Human Factors in Computing Systems. ACM, New York, NY, USA, 1-12.

[30] Jonathan Hook, Sanne Verbaan, Abigail Durrant, Patrick Olivier, and Peter Wright. 2014. A study of the challenges related to DIY assistive technology in the context of children with disabilities. In Proceedings of the 2014 conference on Designing interactive systems. Association for Computing Machinery, New York, NY, USA, 597-606.

[31] Michele Hu. 2015. Exploring New Paradigms for Accessible 3D Printed Graphs. In Proceedings of the 17th International ACM SIGACCESS Conference on Computers \& Accessibility (Lisbon, Portugal) (ASSETS '15). Association for Computing Machinery, New York, NY, USA, 365-366. https: //doi.org/10.1145/2700648.2811330

[32] Amy Hurst and Jasmine Tobias. 2011. Empowering individuals with do-it-yourself assistive technology. In The proceedings of the 13th international ACM SIGACCESS conference on Computers and accessibility. Association for Computing Machinery, New York, NY, USA, 11-18.

[33] Liz Jackson. 2018. We Are the Original Lifehackers. The New York Times (May 2018). https://www.nytimes.com/2018/05/30/opinion/disabilitydesign-lifehacks.html

[34] Amy Kalia, Rose Hopkins, David Jin, Lindsay Yazzolino, Svena Verma, Lotfi Merabet, Flip Phillips, and Pawan Sinha. 2014. Perception of tactile graphics: Embossings versus cutouts. Multisensory research 27, 2 (2014), 111-125.

[35] Jeeeun Kim, Abigale Stangl, and Tom Yeh. 2014. Using LEGO to model 3D tactile picture books by sighted children for blind children. In Proceedings of the 2nd ACM symposium on Spatial user interaction. ACM, New York, NY, USA, 146-146.

[36] Jeeeun Kim and Tom Yehv. 2015. Toward 3D-printed movable tactile pictures for children with visual impairments. In Proceedings of the 33rd Annual ACM Conference on Human Factors in Computing Systems. ACM, New York, NY, USA, 2815-2824. 
[37] I Kocur and S Resnikoff. 2002. Visual impairment and blindness in Europe and their prevention. British fournal of Ophthalmology 86, 7 (2002), 716-722. https://doi.org/10.1136/bjo.86.7.716 arXiv:http://bjo.bmj.com/content/86/7/716.full.pdf

[38] Jan Koprnickỳ, Petr Najman, and Jiři Šafka. 2017. 3D printed bionic prosthetic hands. In 2017 IEEE International Workshop of Electronics, Control, Measurement, Signals and their Application to Mechatronics (ECMSM). IEEE, 1-6.

[39] Alekseï Nikolaevich Leontyev. 1978. Activity, consciousness, and personality. (1978).

[40] Hod Lipson and Melba Kurman. 2010. Factory@ home: The emerging economy of personal fabrication. A report commissioned by the US Office of Science and Technology Policy (2010).

[41] Patricia S Moyer. 2001. Are we having fun yet? How teachers use manipulatives to teach mathematics. Educational Studies in mathematics 47, 2 (2001), 175-197.

[42] Lora Oehlberg, Wesley Willett, and Wendy E Mackay. 2015. Patterns of physical design remixing in online maker communities. In Proceedings of the 33rd Annual ACM Conference on Human Factors in Computing Systems. ACM, New York, NY, USA, 639-648.

[43] Jeremiah Parry-Hill, Patrick C Shih, Jennifer Mankoff, and Daniel Ashbrook. 2017. Understanding volunteer at fabricators: opportunities and challenges in diy-at for others in e-nable. In Proceedings of the 2017 CHI Conference on Human Factors in Computing Systems. ACM, New York, NY, USA, 6184-6194.

[44] Kylie Peppler, Erica Halverson, and Yasmin B Kafai. 2016. Makeology: Makerspaces as learning environments (Volume 1). Vol. 1. Routledge.

[45] J Serrano-Mira, J Gual-Ortí, G Bruscas-Bellido, and JV Abellán-Nebot. 2017. Use of additive manufacturing to obtain moulds to thermoform tactile graphics for people with visual impairment. Procedia Manufacturing 13 (2017), 810-817.

[46] Lei Shi, Yuhang Zhao, and Shiri Azenkot. 2017. Markit and Talkit: a low-barrier toolkit to augment 3D printed models with audio annotations. In Proceedings of the 30th Annual ACM Symposium on User Interface Software and Technology. ACM, New York, NY, USA, 493-506.

[47] Alexa F Siu, Son Kim, Joshua A Miele, and Sean Follmer. 2019. shapeCAD: An accessible 3D modelling workflow for the blind and visually-impaired via 2.5 D shape displays. In The 21st International ACM SIGACCESS Conference on Computers and Accessibility. ACM, New York, NY, USA, 342-354.

[48] Karin Slegers, Kristel Kouwenberg, Tereza Loučova, and Ramon Daniels. 2020. Makers in Healthcare: The Role of Occupational Therapists in the Design of DIY Assistive Technology. In Proceedings of the 2020 CHI Conference on Human Factors in Computing Systems. 1-11.

[49] Katta Spiel, Emeline Brulé, Christopher Frauenberger, Gilles Bailley, and Geraldine Fitzpatrick. 2020. In the details: the micro-ethics of negotiations and in-situ judgements in participatory design with marginalised children. CoDesign 16, 1 (2020), 45-65.

[50] Abigale Stangl, Ann Cunningham, Lou Ann Blake, and Tom Yeh. 2019. Defining Problems of Practices to Advance Inclusive Tactile Media Consumption and Production. In The 21st International ACM SIGACCESS Conference on Computers and Accessibility (Pittsburgh, PA, USA) (ASSETS '19). Association for Computing Machinery, New York, NY, USA, 329-341. https://doi.org/10.1145/3308561.3353778

[51] Abigale Stangl, Chia-Lo Hsu, and Tom Yeh. 2015. Transcribing Across the Senses: Community Efforts to Create 3D Printable Accessible Tactile Pictures for Young Children with Visual Impairments. In Proceedings of the 17th International ACM SIGACCESS Conference on Computers and Accessibility (Lisbon, Portugal) (ASSETS '15). Association for Computing Machinery, New York, NY, USA, 127-137. https://doi.org/10.1145/2700648.2809854

[52] Abigale Stangl, Brian Jernigan, and Tom Yeh. 2015. Write, design, and 3D print tactile stories for visually impaired: Critical making in a middle school classroom. In FabLearn Conference Proceedings.

[53] Abigale Stangl, Jeeeun Kim, and Tom Yeh. 2014. 3D printed tactile picture books for children with visual impairments: a design probe. In Proceedings of the 2014 conference on Interaction design and children. Association for Computing Machinery, New York, NY, USA, 321-324.

[54] Saiganesh Swaminathan, Thijs Roumen, Robert Kovacs, David Stangl, Stefanie Mueller, and Patrick Baudisch. 2016. Linespace: A sensemaking platform for the blind. In Proceedings of the 2016 CHI Conference on Human Factors in Computing Systems. Association for Computing Machinery, New York, NY, USA, 2175-2185.

[55] Lauren Thevin and Anke M Brock. 2018. Augmented reality for people with visual impairments: Designing and creating audio-tactile content from existing objects. In International Conference on Computers Helping People with Special Needs. Springer, 193-200.

[56] Cesar Torres, Wilmot Li, and Eric Paulos. 2016. ProxyPrint: Supporting Crafting Practice through Physical Computational Proxies. In Proceedings of the 2016 ACM Conference on Designing Interactive Systems. 158-169.

[57] Cristen Torrey, David W McDonald, Bill N Schilit, and Sara Bly. 2007. How-To pages: Informal systems of expertise sharing. In ECSCW 2007. Springer, 391-410.

[58] Erik H. Trainer, Arun Kalyanasundaram, Chalalai Chaihirunkarn, and James D. Herbsleb. 2016. How to Hackathon: Socio-Technical Tradeoffs in Brief, Intensive Collocation. In Proceedings of the 19th ACM Conference on Computer-Supported Cooperative Work \& Social Computing (San Francisco, California, USA) (CSCW '16). Association for Computing Machinery, New York, NY, USA, 1118-1130. https://doi.org/10.1145/2818048.2819946

[59] United States. 2012. Assistive Technology Act Technology-Related Assistance for Individuals with Disabilities Act (Tech Act).

[60] Lev Semenovich Vygotsky. 1980. Mind in society: The development of higher psychological processes. Harvard university press.

[61] Bess Williamson. 2020. Accessible America: A history of disability and design. Vol. 2. NYU Press.

[62] World Health Organization. 2011. Visual Impairment and blindness Fact Sheet $N^{\circ} 282$. Technical Report. World Health Organization. 